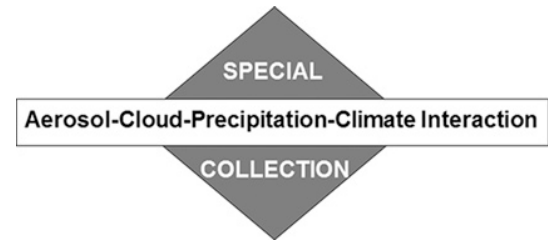

\title{
Can the Impact of Aerosols on Deep Convection be Isolated from Meteorological Effects in Atmospheric Observations?
}

\author{
WOJCIECH W. GRABOWSKI \\ Mesoscale and Microscale Meteorology Laboratory, National Center for Atmospheric Research, \\ Boulder, Colorado
}

(Manuscript received 4 April 2018, in final form 5 July 2018)

\begin{abstract}
Influence of pollution on dynamics of deep convection continues to be a controversial topic. Arguably, only carefully designed numerical simulations can clearly separate the impact of aerosols from the effects of meteorological factors that affect moist convection. This paper argues that such a separation is virtually impossible using observations because of the insufficient accuracy of atmospheric measurements and the fundamental nature of the interaction between deep convection and its environment. To support this conjecture, results from numerical simulations are presented that apply modeling methodology previously developed by the author. The simulations consider small modifications, difficult to detect in observations, of the initial sounding, surface fluxes, and large-scale forcing tendencies. All these represent variations of meteorological conditions that affect deep convective dynamics independently of aerosols. The setup follows the case of daytime convective development over land based on observations during the Large-Scale BiosphereAtmosphere (LBA) field project in Amazonia. The simulated observable macroscopic changes of convection, such as the surface precipitation and upper-tropospheric cloudiness, are similar to or larger than those resulting from changes of cloud condensation nuclei from pristine to polluted conditions studied previously using the same modeling case. Observations from Phase III of the Global Atmospheric Research Program Atlantic Tropical Experiment (GATE) are also used to support the argument concerning the impact of the large-scale forcing. The simulations suggest that the aerosol impacts on dynamics of deep convection cannot be isolated from meteorological effects, at least for the daytime development of unorganized deep convection considered in this study.
\end{abstract}

\section{Introduction}

The impact of atmospheric aerosols on clouds and precipitation continues to be a subject of considerable debate in modeling and observations; see Tao et al. (2012) and Fan et al. (2016) for recent reviews. Arguably, the most controversial subject concerns the impact of aerosols on the dynamics of deep convection, typically referred to as convection invigoration in polluted environments (e.g., Andreae et al. 2004; Rosenfeld et al. 2008). The invigoration is argued to come from the enhanced latent heating when large amounts of liquid water freeze after being transported above the $0^{\circ} \mathrm{C}$ level by convective updrafts, followed by offloading of the frozen condensate through precipitation processes. The freezing alone is not sufficient to invigorate convective updrafts, as it merely

Corresponding author: Wojciech W. Grabowski, grabow@ucar. edu balances the condensate loading associated with liquid water carried through the $0^{\circ} \mathrm{C}$ level. ${ }^{1}$ The invigoration is argued to occur when collision-coalescence is suppressed in the lower portions of polluted deep convective clouds as a result of high droplet concentrations and reduced droplet sizes. The invigoration is argued to significantly increase upper-tropospheric cloud coverage and surface precipitation (e.g., Rosenfeld et al. 2008).

\footnotetext{
${ }^{1}$ The density potential temperature, the measure of parcel buoyancy, is given by $\theta\left(1+\varepsilon q_{v}-q\right)$ where $\theta, q_{v}$, and $q$ are the potential temperature, water vapor mixing ratio, and the sum of all mixing ratios for cloud and precipitation. If $\Delta q$ is the mixing ratio of the liquid condensate carried by the updraft across the freezing level, the "penalty" on the buoyancy is $-\theta \Delta q$. The latent heating due to freezing $\Delta q$ is $L_{f} \Delta q \theta /\left(c_{p} T\right)$ ( $L_{f}$ is the latent heat of freezing, $c_{p}$ is the air specific heat at constant pressure, and $T$ is the air temperature corresponding to $\theta$ ). The absolute values of the two are approximately equal.
} 
Numerical modeling is well suited to investigate the invigoration hypothesis because the simulations can be set up in such a way that the only difference comes from aerosols. However, the simulations need to be representative of clouds that develop in nature. Short (e.g., 1-2 h) small-domain single-cloud simulations with open lateral boundaries and initiated in an idealized way (e.g., through a temperature or moisture perturbation, like a buoyant bubble) are not appropriate because they merely reproduce initial cloud response and exclude realistic interactions between clouds and their environment. Examples of such simulations include those of Khain and Pokrovsky (2004), Khain et al. (2005), and Teller and Levin (2006), among many others. However, in nature, convective clouds continuously interact with their surroundings through gravity waves and detrainment that modify their environment (e.g., Bretherton and Smolarkiewicz 1989). These interactions affect development of subsequent clouds. Thus, it is irrelevant what the first cloud does, but what matters is a response of an ensemble of clouds to realistic forcings averaged over many cloud realizations. (An exception to this argument might be when the first cloud causes a regime change; this does not apply to the case considered here.) The forcings refer to a prescribed initial meteorological situation (e.g., the sounding), surface sensible and latent heat fluxes, radiative cooling of the atmosphere, and the large-scale advection of temperature and moisture. The latter can be included through realistic lateral boundary conditions [as in typical limited-area numerical weather prediction (NWP) simulations] or through prescribed tendencies imposed over a finite-extent horizontal domain with periodic lateral boundaries [i.e., as in the cloud-resolving modeling (CRM) approach; e.g., Grabowski et al. 1996, 1998; Xu and Randall 1996]. Examples of the NWP-type simulations that explicitly consider effects of aerosols are Seifert et al. (2012), Fan et al. (2013), and Gayatri et al. (2017). These show a small impact on the surface precipitation (typically a mere few percent) and a significant impact on simulated cloud properties. Examples of the CRM-type simulations targeting aerosol effects are those of Tao et al. (2007) and references therein, Morrison and Grabowski (2011), and Grabowski and Morrison (2016; hereinafter GM16). Using a novel modeling methodology referred to as "piggybacking" applied to the case of daytime convective development over land based on observations during the Large-Scale Biosphere-Atmosphere (LBA) field project in Amazonia, GM16 show that simulated differences between pristine (PRI) and polluted (POL) clouds come mostly from microphysical considerations, namely, the increased cloud droplet concentrations in polluted conditions leading to the increased ice crystal concentrations and, consequently, smaller ice fall velocities and thus longer persistence of upper-tropospheric anvils [i.e., as previously argued in Morrison and Grabowski (2011)]. No impact on convective dynamics above the freezing level and thus no convective invigoration has been shown in GM16.

Evaluation of aerosol effects on clouds is difficult in observations because it is difficult to ensure that the differences in aerosols are not accompanied by differences in meteorological conditions, such as temperature and moisture profiles, surface fluxes, and the presence of large-scale perturbations that destabilize the atmosphere and provide additional forcing for convection. The observed correlations between cloud and aerosol properties may be coincidental and not causal, that is, aerosols and clouds may simply vary together, for instance, as a result of meteorological conditions covarying with the aerosols. One example of the flawed interpretation of cloud, aerosol, and meteorological observations is the analysis of the data collected at the DOE Atmospheric Radiation Measurement (ARM) Program Southern Great Plains (SGP) site presented in Li et al. (2011). The data clearly show correlation between clouds and aerosols, but Li et al. (2011) go one step further and suggest that there is a causal relationship between the two (e.g., see in the abstract: "precipitation frequency and rain rate are altered by aerosols"; "are altered" being the key phrase). Varble (2018) shows that the correlations observed in the ARM SGP data can be simply explained by the covariability of aerosols and relevant meteorological conditions, such as convective available potential energy (CAPE; the vertical integral of the positive pseudoadiabatic parcel buoyancy) or level of neutral buoyancy. Storer et al. (2014) are more cautious, but they do say (see the abstract), "These observations suggest that convective invigoration occurs with increased aerosol loading, leading to deeper, stronger storms in polluted environments" (with the word "leading" implying the causality).

Although many studies recognize the role of meteorology as a potential driver of observed convectionaerosol correlations (e.g., Koren et al. 2010; Storer et al. 2014), the key issues are whether the observations can establish the impact of meteorology with sufficient accuracy and if the observed parameters typically used to describe convection (e.g., CAPE) provide sufficient separation between cases with different surface precipitation and upper-tropospheric clouds. For instance, for tropical convection, differences in the atmospheric temperature profile above the boundary layer are small between periods without surface precipitation and periods with significant rain. This is referred to as the weak temperature gradient approximation for the tropical 
atmosphere (e.g., Sobel et al. 2001). Over land, small changes to the surface fluxes (i.e., the partitioning between the latent and sensible components) may affect modifications of cloudiness and precipitation in a way similar to aerosols. Finally, additional forcing due to large-scale mean ascent strongly affects convection, and it may be impossible to detect in observations.

To address the key issues above, we use a cloud model and extend the piggybacking methodology that allows separating impacts of various factors affecting convection with high fidelity (see GM16 and references therein). However, rather than changing aerosols as in GM16, we include small changes to the sounding and surface fluxes, and we add a weak large-scale ascent, all difficult to infer from observations. We compare simulated changes in cloudiness and precipitation to those caused by aerosols in GM16. The crux of the argument is that by including the small changes to "meteorology" (i.e., the sounding, the surface flux, and the large-scale ascent) we can compare meteorological effects to the effects of aerosols. If simulated meteorological impacts on clouds and precipitation are similar to aerosol effects, and perturbations of the convective environment are smaller than what can be distinguished in observations, then one can conclude that the impact of meteorological conditions cannot be separated from the effects of aerosols. We argue that this is indeed the case in simulations presented in this paper.

The next section discusses the modeling setup and introduces the cases applied in piggybacking simulations. Simulation results are discussed in section 3 . One of the key results is that the presence of undetectable large-scale ascent significantly affects surface precipitation and cloudiness with virtually no impact on CAPE. This is reminiscent of the way deep convection interacts with its environment in the tropical atmosphere. To strengthen the argument about inseparable effects of aerosols and meteorology, we bring in section 4 observations from Phase III of the Global Atmospheric Research Program Atlantic Tropical Experiment (GATE). These observations provide strong support for the conclusions drawn from numerical simulations. A brief summary and discussions in section 5 concludes the paper.

\section{The model and modeling setup}

The cloud model and modeling setup are the same as in Grabowski (2015) and GM16. The model is a simplified serial version of the 3D nonhydrostatic anelastic Euleriansemi-Lagrangian (EULAG) model (http://www.mmm.ucar. edu/eulag). The modeling setup mimics daytime convective development over warm-season continents because of strongly increasing surface latent and sensible heat fluxes.
The simulations feature formation of a convective boundary from the stably stratified morning sounding, development of shallow convection after a couple hours, and transition from shallow to deep convection around local noon. Only dissipating upper-tropospheric anvil clouds exist at the end of the 12-h simulations (i.e., from 0730 to 1930 local time). The evolving sensible and latent surface fluxes in the basic setup are as in Grabowski et al. (2006). Details of the model setup are as in GM16. A periodic horizontal domain of $50 \mathrm{~km}$ by $50 \mathrm{~km}$ is covered by a uniform $400-\mathrm{m}$ grid. In the vertical, the domain extends up to $24 \mathrm{~km}$, applying 81 levels with a stretched grid. The vertical grid length is around $100 \mathrm{~m}$ near the surface, with about a dozen levels below $1.5 \mathrm{~km}$. The grid length increases to about 300 and $400 \mathrm{~m}$ at 5 and $15 \mathrm{~km}$, respectively. The model time step is $4 \mathrm{~s}$.

The key feature of the simulations is the application of the double-moment warm-rain and ice microphysics schemes of Morrison and Grabowski (2007, 2008a,b) that explicitly predict the in-cloud supersaturation and include cloud condensation nuclei (CCN) activation linking the concentration of cloud droplets to the assumed CCN characteristics. As discussed in GM16, lower supersaturations inside polluted convective updrafts are the main reason for the simulated about $10 \%$ increase of the surface precipitation in the polluted case when compared to pristine conditions. In addition, higher droplet concentrations in polluted clouds lead to higher upper-tropospheric ice concentrations and thus longer persistence of polluted anvils. For the simulations discussed in this paper, the pristine double-mode CCN spectrum is assumed as in section 4 in GM16. The first mode is described by total $\mathrm{CCN}$ number mixing ratio of $100 \mathrm{mg}^{-1}$, and the mean dry radius, geometric standard deviation of the distribution, and the soluble fraction are assumed as $0.05 \mu \mathrm{m}, 2.0$, and 0.7 , respectively. For the second mode, the total $\mathrm{CCN}$ number mixing ratio is taken as $500 \mathrm{mg}^{-1}$ and the mean dry radius of $0.01 \mu \mathrm{m}$; other parameters for the second mode are the same as for the first mode. As shown in GM16, only some of the $\mathrm{CCN}$ from the second mode are activated in the strongest updrafts (cf. Fig. 13 therein). This is arguably more realistic when compared to GM16 simulations with only a single CCN mode that was fully activated in strong updrafts, as shown in Fig. 9 therein. $\mathrm{CCN}$ processing by clouds is not considered, and $\mathrm{CCN}$ characteristics remain unchanged as the simulation progresses.

We expand the piggybacking methodology applied in shallow convection simulations of Grabowski (2014) and Grabowski and Jarecka (2015) and in deep convection simulations of Grabowski (2015), GM16, and Grabowski and Morrison (2017) that focused on the cloud microphysics. In contrast, we keep the microphysics the same in all simulations presented here (the pristine double-mode 
$\mathrm{CCN}$ case from section 4 of GM16, as explained above) and change specific details of meteorological conditions in which convection develops. These modifications are discussed in detail below.

The piggybacking methodology involves applying two sets of thermodynamic variables (the potential temperature, water vapor mixing ratio, and all variables describing aerosol, cloud, and precipitation particles) in a single cloud-field simulation. The first set is coupled to the dynamics and drives the simulation (set D, as in "driving"), and the second set piggybacks the simulated flow and does not affect it (set P, as in "piggybacking"). From the point of view of the $\mathrm{P}$ set of thermodynamic variables, the piggybacking is similar to the kinematic model approach, that is, using thermodynamic variables within a prescribed flow (e.g., Szumowski et al. 1998; Morrison and Grabowski 2007, 2008b; Slawinska et al. 2009). However, the key difference is that the flow for $\mathrm{P}$ set in piggybacking comes from realistic three-dimensional cloud-field simulations driven by the D set. In addition, an important element of the piggybacking approach is swapping microphysical sets so the D set becomes the $\mathrm{P}$ set, and vice versa. Piggybacking allows for assessing the impacts with high fidelity, and it is capable of detecting even minuscule impacts on bulk cloud properties, such as the cloud cover, liquid and ice water path, and surface precipitation. It also allows for comparing local cloud buoyancies between D and P sets and thus exploring possible impacts on the cloud dynamics (see GM16). Comparing results from D sets and differences between results from the $\mathrm{D}$ and $\mathrm{P}$ sets in the two simulations (i.e., in the original simulation and in the one with sets swapped) highlights the impact on the dynamics.

Piggybacking simulations apply five cases, with all simulations using the same microphysics as explained above. Cases (ii)-(v) apply small modification of case (i), the control (CNTR). Below are details of the cases with explanations of the changes:

(i) Control case referred to as CNTR. This is the basic setup described in Grabowski et al. (2006) as applied in section 4 of GM16.

(ii) The case with a warmer sounding is referred to as SNDG. In this case, the temperature of the initial sounding is increased by $1 \mathrm{~K}$ at all levels keeping the relative humidity the same. The precipitable water (i.e., the total water vapor in the column) increases from about 31.4 to $33.7 \mathrm{~kg} \mathrm{~m}^{-2}$, that is, about $7 \%$ in agreement with the ClausiusClapeyron scaling. Thus, there is more water vapor that convection can work with. In addition, the initial CAPE (to be shown later) is increased as well. The motivation for the SNDG comes from an expectation that the initial temperature profile has a significant impact on the subsequent convective development.

(iii) The case with a drier sounding is referred to as RHUM. The relative humidity of the initial sounding is reduced by $5 \%$ above $2 \mathrm{~km}$. This reduces the precipitable water from 31.4 to $30.4 \mathrm{~kg} \mathrm{~m}^{-2}$, that is, by about $3 \%$. The motivation for the RHUM comes from the documented sensitivity of moist convection to the free-tropospheric humidity (e.g., Derbyshire et al. 2004; Takemi et al. 2004). However, the 5\% change of the relative humidity is small and would be difficult to detect in observations (Nash 2015).

(iv) The case with the modified surface heat fluxes is referred to as SFLX. The original formulation in CNTR applies algebraic functions to represent time evolutions of the sensible and latent heat fluxes (see appendix in Grabowski et al. 2006). The maximum fluxes are 270 and $554 \mathrm{~W} \mathrm{~m}^{-2}$ for sensible and latent components, respectively. The resulting Bowen ratio (i.e., the ratio between sensible and latent flux components) is about 0.49. In the SFLX case, the latent flux is reduced by about $10 \%$, and the sensible flux is increased by about $20 \%$ to keep the total surface heat flux unchanged. The resulting maximum fluxes are 324 and $500 \mathrm{~W} \mathrm{~m}^{-2}$ for sensible and latent components, and the Bowen ratio is increased to 0.65. As shown in Thomas et al. (2018), the ratio of the surface buoyancy flux (BF) to the total surface heat flux $(\mathrm{HF})$ depends on the Bowen ratio $(\mathrm{Br})$ as $\mathrm{BF} / \mathrm{HF}=(\alpha+\mathrm{Br}) /(1+\mathrm{Br})$, where $\alpha \approx 0.1 . \mathrm{BF} / \mathrm{HF}$ changes from 0.40 in CNTR to 0.45 in SFLX; that is, there is about $10 \%$ more surface buoyancy forcing in SFLX when compared to CNTR. The motivation for the SFLX case is that the surface buoyancy flux determines the evolution of the boundary layer and may impact development of deep convection [see discussion in Thomas et al. (2018) that highlights differences between premonsoon and monsoon convection over the Indian subcontinent].

(v) The case with additional large-scale temperature and water vapor forcing is referred to as FORC. The additional forcing comes from a large-scale ascent between the surface and height of $L=10 \mathrm{~km}$ given by $w_{0} \sin (\pi z / L)$ for $0<z<L$ and zero otherwise, with $w_{0}=0.5 \mathrm{~cm} \mathrm{~s}^{-1}$. Solid lines in Fig. 1 show resulting temperature and moisture tendencies when the ascent is applied to the initial sounding. The dashed lines show the approximation of the additional temperature and moisture tendencies that is used through the entire FORC simulations. The motivation for the FORC case is that the presence of a large-scale ascent can 


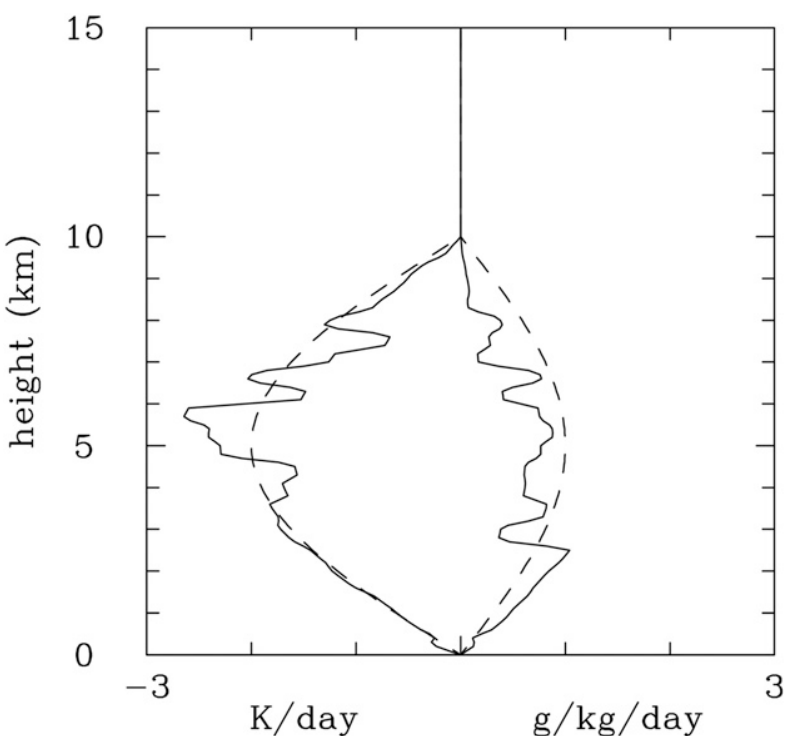

FIG. 1. Temperature and moisture tendencies obtained by applying an updraft between 0 and $10 \mathrm{~km}$ with half-sinusoidal shape and $0.5 \mathrm{~cm} \mathrm{~s}^{-1}$ maximum at $5 \mathrm{~km}$ to the initial temperature and water vapor profiles (solid lines). Half-sinusoidal tendencies approximating solid lines (dashed lines). The amplitudes are $-2 \mathrm{~K} \mathrm{day}^{-1}$ and $1 \mathrm{~g} \mathrm{~kg}^{-1}$ day $^{-1}$.

significantly impact convective development and resulting surface precipitation. Note that the assumed amplitude of the ascent would be difficult to assess from large-scale observations as the continuity equation implies that the assumed assent is associated with the horizontal wind change of about $0.5 \mathrm{~m} \mathrm{~s}^{-1}$ over a distance of $500 \mathrm{~km}$.

The piggybacking simulations are performed applying CNTR as the driver (D-CNTR) and then one of the (ii)-(v) cases as the piggybacker (i.e., P-SNDG, P-RHUM, P-SFLX, and P-FORC). Subsequently, one of the (ii)-(iv) cases is used as a driver (i.e., D-SNDG, D-RHUM, D-SFLX, and D-FORC) and CNTR as piggybacker (P-CNTR). As in section 4 of GM16, we use three member mini-ensembles to improve the robustness of the piggybacking results and to alleviate the impact of a relatively small horizontal domain applied here (typically only a few deep convective clouds coexist in the period of the strongest forcing). Different ensemble members are generated by applying different sequences of random numbers that are used in temperature and moisture perturbations at the start and are periodically added during the simulation [see Grabowski et al. (2006) for details]. Simulation results are saved as snapshots of model fields every $6 \mathrm{~min}$ of the simulation time. Surface precipitation is saved every $3 \mathrm{~min}$ as the average over all time steps from the preceding 3-min period. These archives provide data for the analysis presented in the next section.

\section{Results and discussion}

For the reader's convenience, Fig. 2 shows results from GM16 (Fig. 12 therein; with some modifications) to put in context results from simulations completed for this study. This figure shows the evolution of the cloud fraction profiles and surface rain accumulations in piggybacking simulations contrasting pristine and polluted double-mode CCN distribution discussed in section 4 of GM16. The focus on the cloud fraction (especially for the uppertropospheric clouds) and on the surface precipitation comes from the fact that these two observables (e.g., applying satellite or ground-based remote sensing) are used in observations of aerosol impact on convection. The cloud fraction profiles document the development of shallow convection in the first few hours of the simulations, transition from shallow to deep convection between hour 4 and 6 , and only upper-tropospheric anvils present at the end of the simulations. The difference between driver and piggybacker cloud fraction profiles are small prior to hour 8 , and it gradually increases afterward, with anvils in the polluted cases featuring significantly higher cloud fractions. The latter was argued in GM16 to originate from differences in cloud droplet concentrations leading to differences in ice concentrations and thus mean ice particle sizes. As a result, upper-tropospheric anvils in polluted simulations feature slower ice sedimentation rates and thus higher cloud fractions. Polluted simulations have about $10 \%$ higher surface rain accumulations, as shown by the individual driver minus piggybacker evolutions in the bottom-right panel. The small difference in the latter (i.e., D-POL minus P-PRI being larger in the absolute sense than D-PRI minus P-POL at hour 12) suggests an impact on convective dynamics. This is argued in GM16 to come from smaller supersaturations and thus larger buoyancies in the warm-rain zone below the freezing level (see Fig. 13 therein). The surface precipitation difference is also shown by the dashed line in the bottom-right panel that documents the ensemble-mean difference $\langle\mathrm{D}-\mathrm{PRI}\rangle$ minus $\langle\mathrm{D}-\mathrm{POL}\rangle$ evolution. However, the ensemble is small and thus the ensemble spread is large, as shown by the hourly values of the ensemble-mean standard deviation. This highlights the strength of the piggybacking methodology.

As explained in the previous section, the piggybacking simulations completed for this study include small modifications of the PRI setup referred to as CNTR here. Below, we discuss the results.

\section{a. CNTR versus SNDG}

Figure 3 shows results from the CNTR-SNDG miniensemble in the format of Fig. 2. Differences between driver and piggybacker cloud fraction profiles are small and difficult to see in the figure. The most significant 

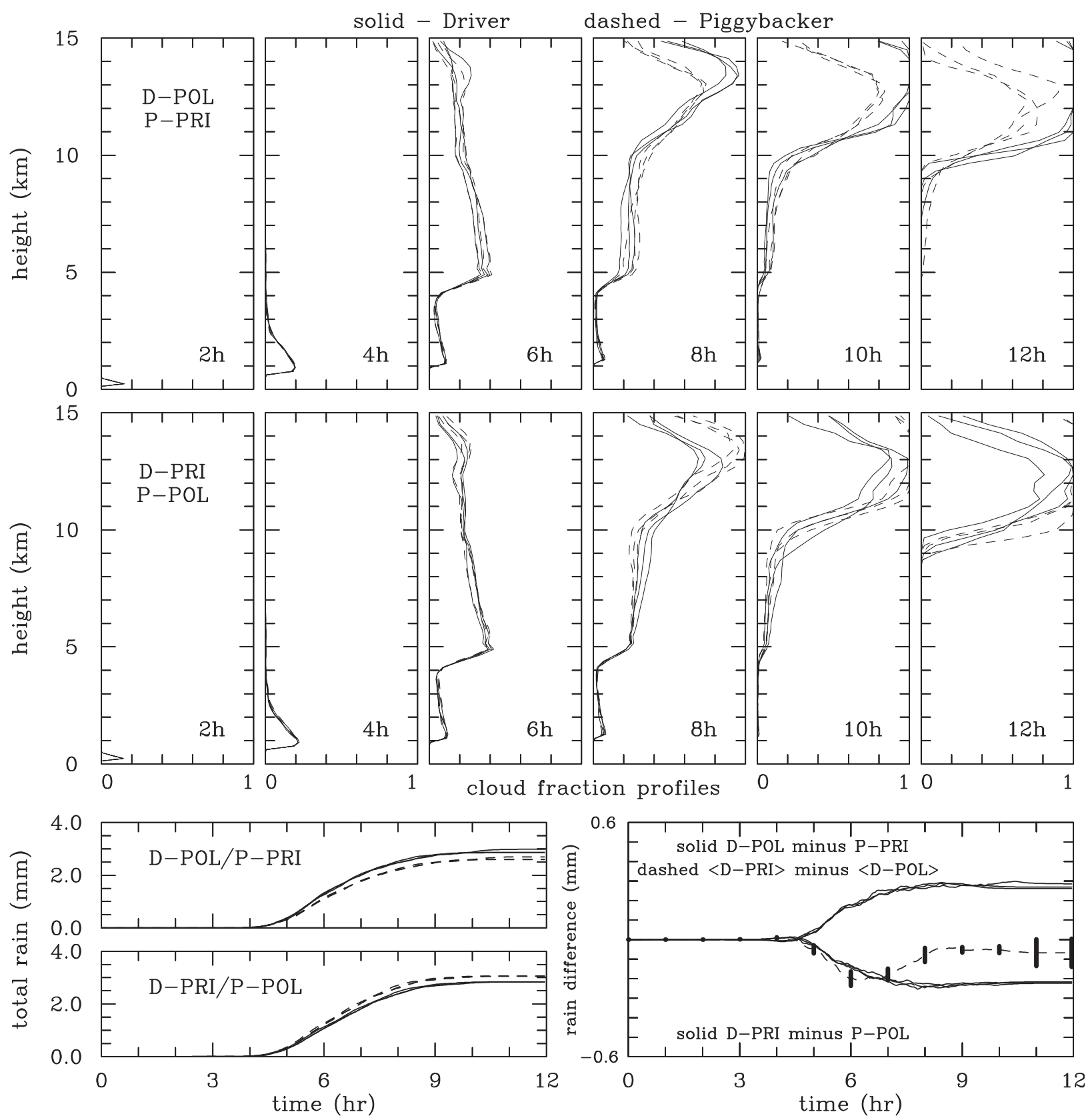

FIG. 2. Results from PRI vs POL three-member mini-ensemble simulations from GM16. (top row) Instantaneous cloud fraction profiles in (first row) D-POL-P-PRI and (second row) D-PRI-P-POL piggybacking simulations for hour 2, 4, 6, 8, 10, and 12. Solid and dashed lines are for driver and piggybacker ensemble members, respectively. (bottom left) Evolution of the surface rain accumulations for drivers (solid lines) and piggybackers (dashed lines). (bottom right) The difference between driver and piggybacker in six pairs of piggybacking simulations (solid lines); ensemble-mean difference between drivers in PRI and POL (dashed line), with thick vertical lines showing twice the mean ensemble spread every hour.

difference comes from switching the driver from CNTR to SNDG, with SNDG featuring higher uppertropospheric cloud fractions starting at hour 6 . This is reminiscent of the difference between drivers in the polluted and pristine simulations in GM16 shown in Fig. 2 above. However, the differences in CNTR versus
SNDG have a different origin, as explained below. The mean surface rain accumulations at the end of the simulations differ between CNTR and SNDG by about $0.1 \mathrm{~mm}$, that is, about $3 \%$ of the total accumulation. This is about half of the $7 \%$ increase resulting from $1-\mathrm{K}$ temperature increase. 

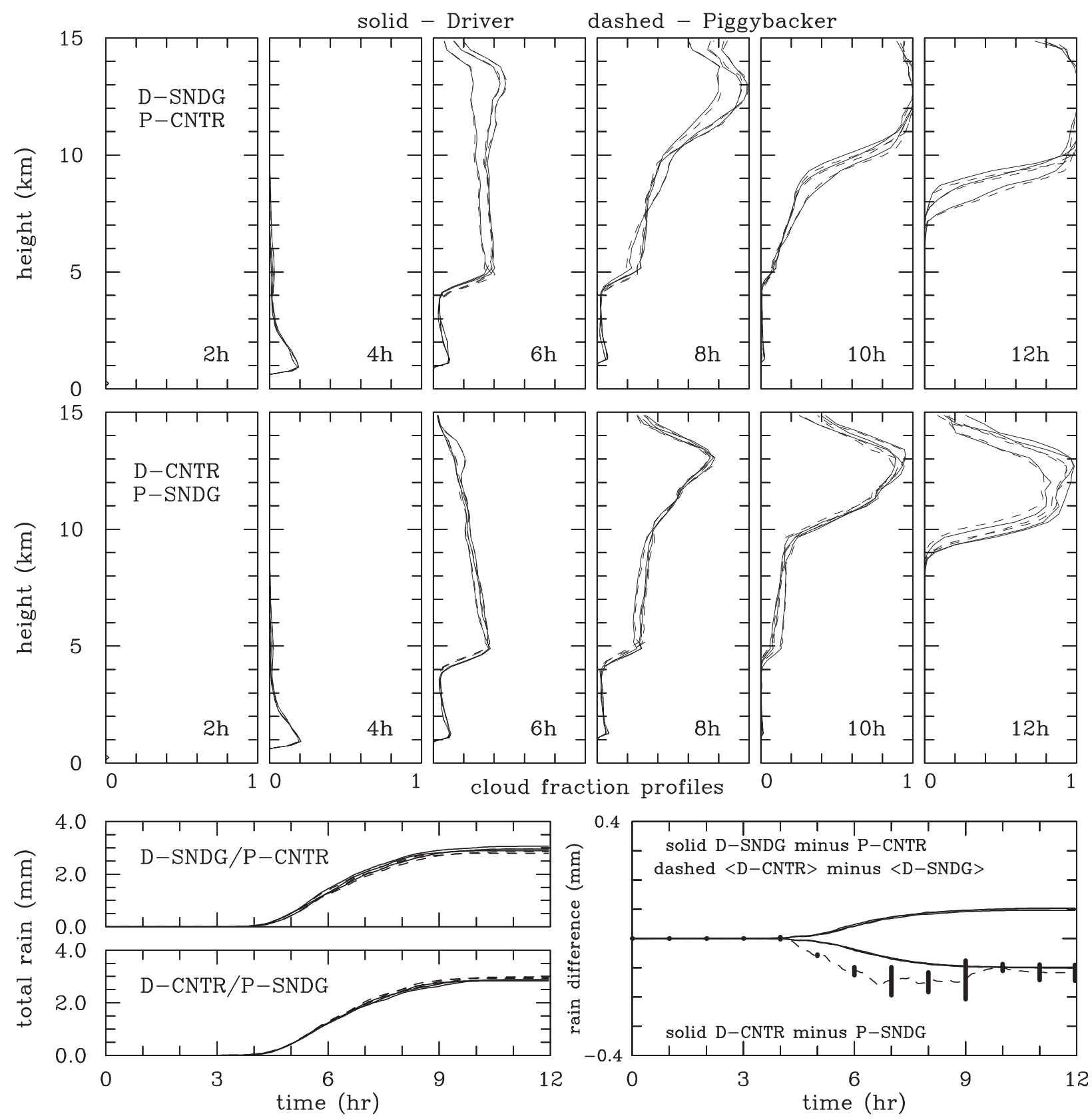

FIG. 3. As in Fig. 2, but for CNTR-SNDG mini-ensemble.

Figure 4 shows the evolution of CAPE and convective inhibition [(CIN) the vertical integral of the absolute value of the lower-tropospheric negative pseudoadiabatic buoyancy] for drivers in CNTR (solid lines) and SNDG (dashed lines) simulations. CAPE and CIN are calculated using initial conditions that come from averaging moisture and temperature over a 500-m-deep layer near the surface. The CAPE is close to $600 \mathrm{~J} \mathrm{~kg}^{-1}$ higher for the SNDG than in CNTR throughout the simulations. This comes from a warmer environment that holds more water vapor. CAPE increases and CIN decreases during the initial $3 \mathrm{~h}$ as the surface fluxes increase and the cloudfree boundary layer deepens. CAPE reaches its maximum during the shallow convection phase when CIN is close to zero. As deep convection develops, CAPE begins to decrease and continues doing so gradually until the end of the simulations. CIN slowly increases during the deep convection and anvil phase.

Systematically larger CAPE in SNDG simulations may suggest stronger updrafts and thus higher cloud 

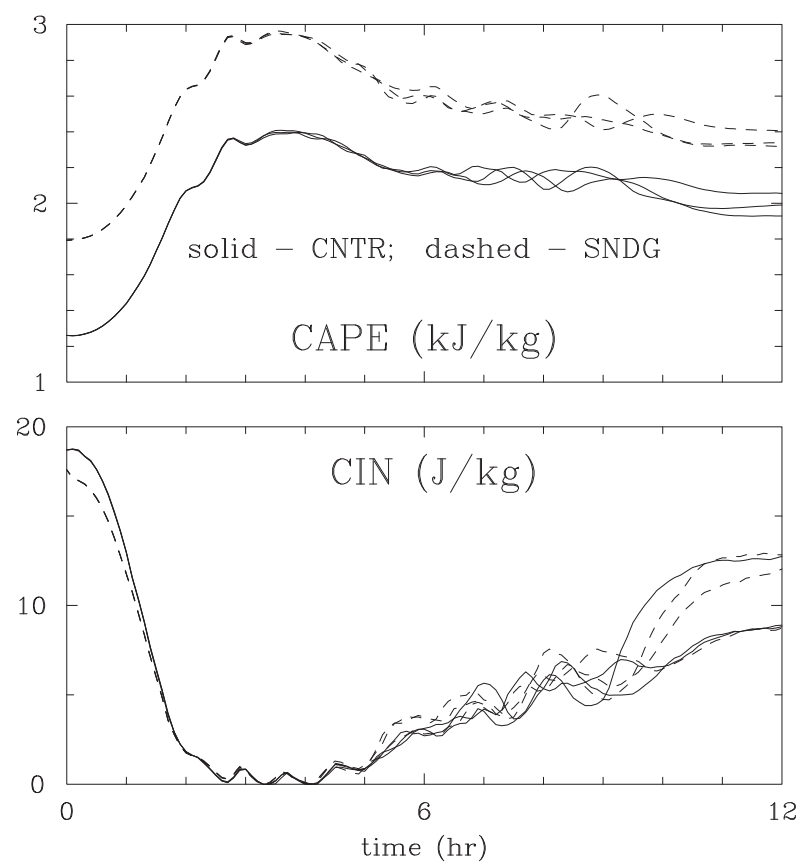

FIG. 4. Evolution of (top) CAPE and (bottom) CIN calculated from domain-averaged temperature and moisture profiles from driver simulations in CNTR (solid lines) and SNDG (dashed lines) cases.

droplet concentrations because of the impact of updraft strength on $\mathrm{CCN}$ activation. Changes of the droplet concentration may also affect the ice concentrations, as in GM16. Since undiluted updraft strength scales with the square root of CAPE, about $50 \%$ larger CAPE in SNDG suggests about $20 \%$ stronger undiluted updrafts. Analysis of the updraft statistics for the period of the strongest convection (i.e., during hours 6 and 7 of the simulation, similar to the one shown in Fig. 11 in GM16) indeed shows statistically significant increase of updraft speeds in the middle and upper troposphere for SNDG when compared to CNTR (not shown). Such an increase can potentially lead to higher droplet concentrations. However, this is really not the case, as shown in Fig. 5. The figure, in the format of Fig. 14 of GM16, shows the variability of the mean upper-tropospheric ice concentration (in an approximately 3-km-deep layer below the cloud top) versus the mean concentration of cloud droplets (in the layer between 2 and $4 \mathrm{~km}$ ) in deep convective columns, defined as columns with a cloud base below $2 \mathrm{~km}$, cloud top above $11 \mathrm{~km}$ (temperature around $-42^{\circ} \mathrm{C}$ ), and maximum vertical velocity in the column larger than $5 \mathrm{~m} \mathrm{~s}^{-1}$. The data come from all time levels between hours 6 and 8, that is, when deep convection is in its maximum strength. The left panel comes from CNTR-SNDG simulations, whereas the right panel comes from Fig. 14 of GM16. As the figure shows, droplet and ice concentrations are similar in CNTR and
SNDG. Thus, the impact on cloud microphysics resulting from modifying the initial sounding is small.

In summary, the $1-\mathrm{K}$ difference in the initial sounding with the same initial relative humidity results in about a $3 \%$ increase of the surface rainfall, about half of the increase following the Clausius-Clapeyron scaling, and the rest of the available water is deposited into convective anvils. This leads to a noticeable increase of the upper-tropospheric cloud fraction when SNDG is driving, as shown in top panels of Fig. 3 .

\section{b. CNTR versus RHUM}

Figure 6, in the format of Figs. 2 and 3, shows outcome of CNTR-RHUM mini-ensembles. For the cloud fraction profiles, the difference between driver and piggybacker are small (with RHUM typically being slightly smaller regardless whether it drives or piggybacks) and-as in SNDG-the most evident impact coming from the difference between driving with CNTR versus driving with RHUM. The latter difference is consistent with a higher environmental humidity allowing entraining clouds to maintain higher cloud buoyancy and depositing more cloud mass into upper-tropospheric anvils. Surface rain accumulation is about $15 \%$ larger in D-CNTR than in D-RHUM, with the driver minus piggybacker being about two-thirds of that.

Because the small reduction of environmental humidity affects CAPE and CIN insignificantly, we do not show their evolutions as they are similar to those for CNTR shown in Fig. 4. The vertical velocity statistics (reflecting realistic cloud conditions as opposed to CAPE that considers the adiabatic parcel) show some differences, with RHUM showing weaker updrafts in the upper troposphere.

In summary, $5 \%$ reduction of the initial relative humidity above the height of $2 \mathrm{~km}$ results in noticeable reduction of the surface precipitation and upper-tropospheric cloudiness. These impacts are comparable to the impact of aerosols simulated in GM16, as shown in Fig. 2.

\section{c. CNTR versus SFLX}

The SFLX setup explores the impact of surface flux uncertainties on the LBA model setup. Arguably, the $10 \%-20 \%$ uncertainty in the partitioning between surface sensible and latent heat fluxes may be considered a judicious estimate for the case of daytime convection development over land, especially if land surface heterogeneities, not considered here, are included.

Figures 7 and 8 , in the same formats as Figs. 2, 3, and 6 and Fig. 4, respectively, illustrate the results from the CNTR-SFLX mini-ensembles. Driving with CNTR setup provides more upper-tropospheric cloudiness in the final few hours of the simulations, although the difference may be argued not statistically significant because of a wide 


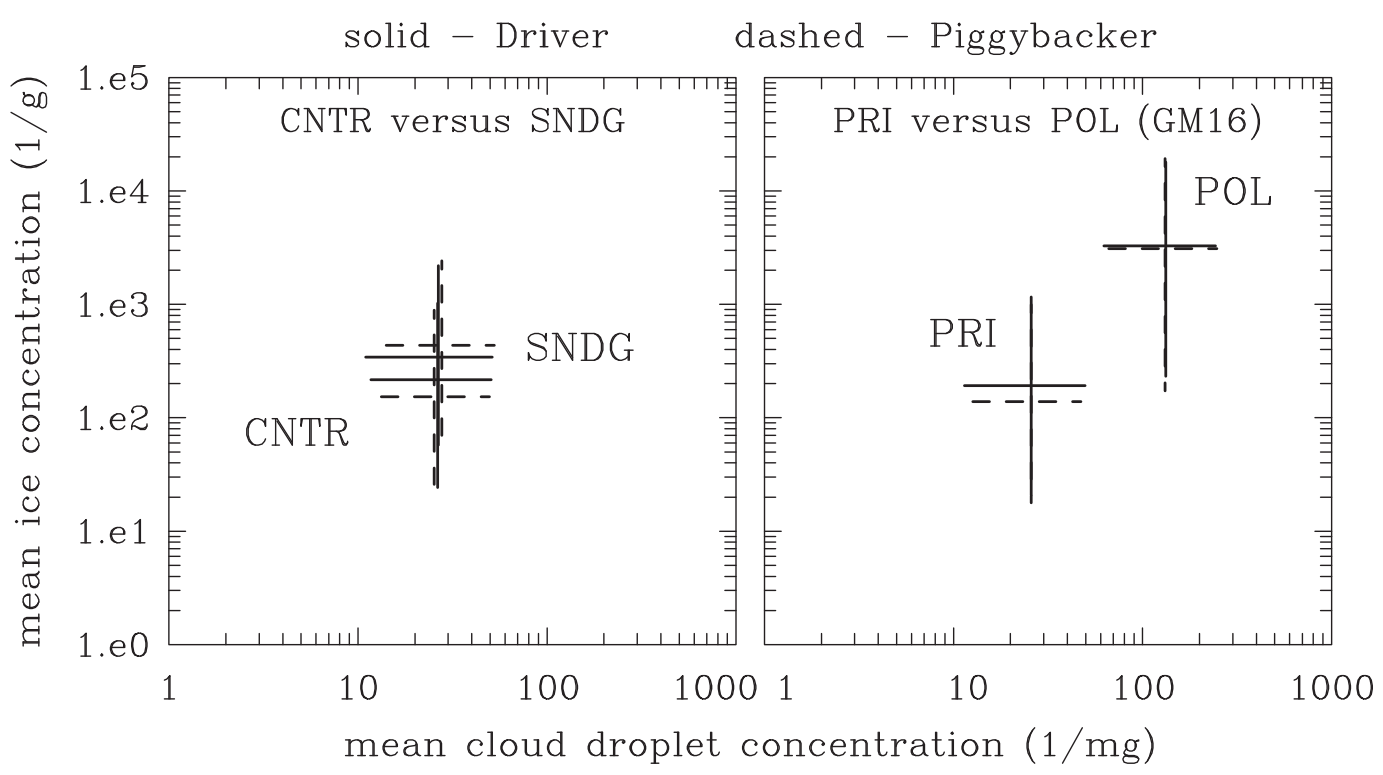

FIG. 5. Mean ice crystal concentration in the upper troposphere as a function of the mean cloud droplet concentration below the freezing level in deep convective columns for (left) CNTR and SNDG simulations and (right) PRI and POL simulations from GM16. Each cross represents the range from the 10th to 90th percentiles, and the intersection is the median value. Solid (dashed) lines are from sets of thermodynamic variables driving (piggybacking) the simulation. The vertical lines in the right panel overlay each other.

spread between ensemble members. As in Figs. 3 and 6, the difference in cloudiness between driver and piggybacker are small. Although difficult to see in the figure, there is a small increase of the cloud-base height that results from the increase of the surface buoyancy flux and reduced surface latent heat flux in panels for hours 4 and 6 (cf. Thomas et al. 2018). The surface rain accumulation is also reduced in SFLX, with the difference, the same regardless which simulation is driving, of about $0.2 \mathrm{~mm}$ (i.e., about $7 \%$ ). Evolutions of CAPE and CIN (Fig. 8) are similar to CNTR in Fig. 4, with a small reduction of CAPE for the SFLX cases. There is no difference in the relationship between droplet and ice concentrations between CNTR and SFLX (not shown), similar to CNTR and SNDG.

Hansen and Back (2015) discuss the impact of changing the surface Bowen ratio on moist convection in convective-radiative quasi equilibrium. They show that that surface Bowen ratio does not change the maximum updraft speed in the quasi equilibrium, but an appreciable change occurs in their 1-day-long simulations started from the tropical oceanic initial sounding. In the initial sounding simulations, Hansen and Back (2015) prescribe the constant total surface flux and vary the Bowen ratio. Our simulations feature surface fluxes that strongly increase with time, and the Bowen ratio change is much smaller than in Hansen and Back. Thus, the effect on convection in our simulations is small, as illustrated by Figs. 7 and 8 .

In summary, $10 \%$ reduction of the surface latent heat flux in SFLX keeping the total flux the same (i.e., increasing the surface Bowen ratio from 0.49 to 0.65 ) leads to a noticeable decrease of the surface rainfall and upper-tropospheric cloudiness. Again, these changes are comparable to the impact of aerosols simulated in GM16.

\section{d. CNTR versus FORC}

Figures 9 and 10 document the impact of additional forcing in the FORC case. Figure 9 shows higher cloud fractions at hours 4,6 , and 8 , and perhaps earlier transition from shallow to deep convection when FORC is the driver (top panels). Upper-tropospheric cloud fraction differences at later times are small. FORC results in more surface rainfall, especially when it drives the simulations (i.e., about $4 \mathrm{~mm}$ in D-FORC versus about $3 \mathrm{~mm}$ in D-CNTR). The driver-piggybacker difference is about $0.5 \mathrm{~mm}$, that is, about half of the difference between the drivers. This is consistent with the additional forcing that destabilizes the atmosphere and provides an additional source of moisture that can be converted to precipitation. However, the differences in CAPE are small, as shown in Fig. 10. CAPE is marginally larger in FORC before deep convection develops, and smaller thereafter, arguably because of the impact of larger rainfall on the mean near-surface conditions. The small impact on CAPE can be interpreted as an insignificant impact on the mean temperature profile. We will return to this issue in section 4 .

The impact on the surface rainfall, cloud fraction profiles, and CAPE in FORC can be understood using the 

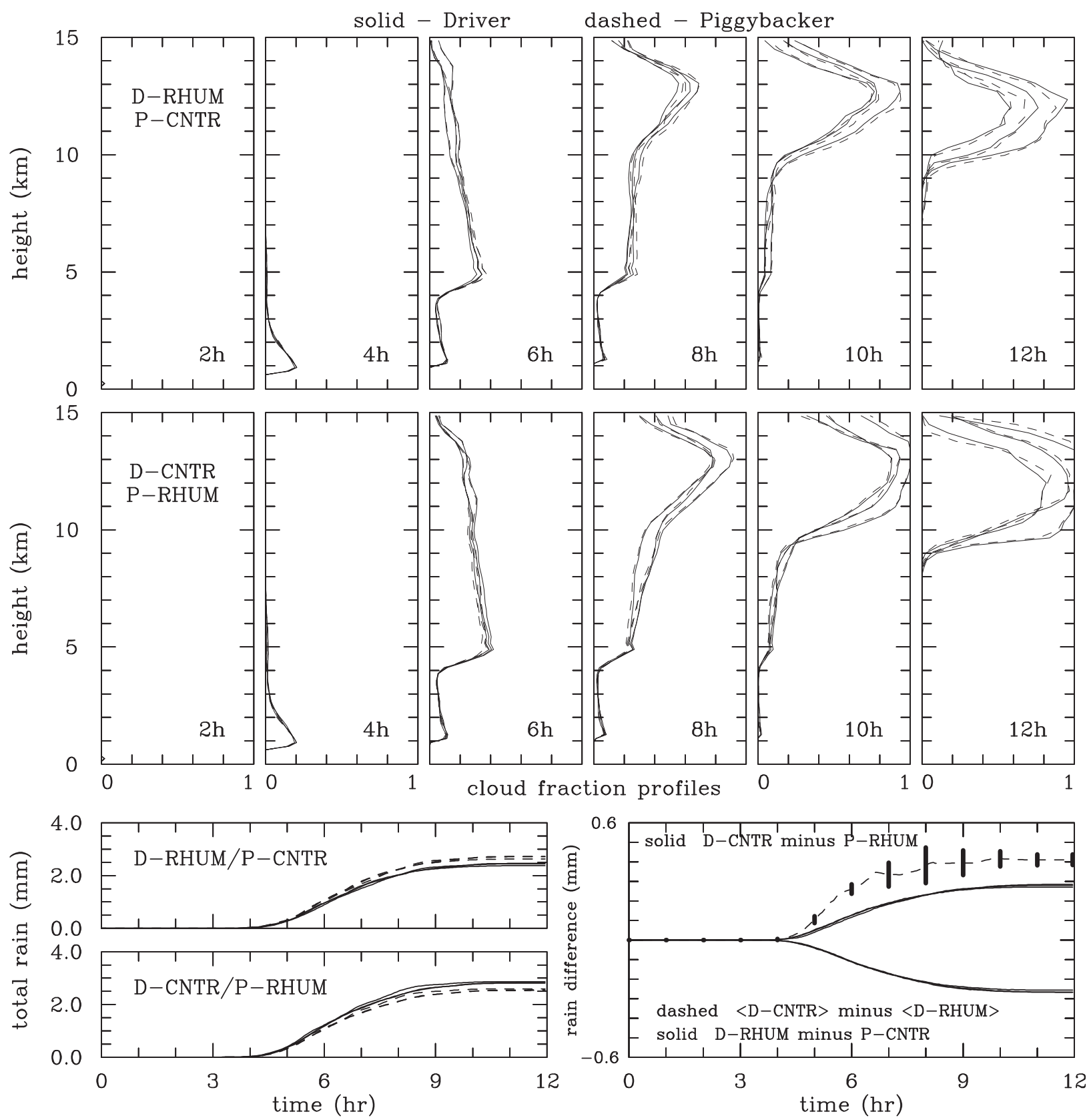

FIG. 6. As in Fig. 2, but for the CNTR-RHUM mini-ensemble.

moist convective scaling discussed in Robe and Emanuel (1996). They completed a series of CRM simulations in which simulated moist convection changed in response to imposed large-scale cooling, from 1 to over $6 \mathrm{~K} \mathrm{day}^{-1}$. The increased cooling resulted in equilibrium states with increased updraft cloud mass fluxes, as one might expect. The increased mass fluxes come from the increased area coverage of convective drafts and approximately unchanged mean updraft velocity; see Fig. 7 therein. The latter was due to small changes of CAPE (Fig. 10 therein), especially for cooling rates larger than $2 \mathrm{~K} \mathrm{day}^{-1}$. Although simulations discussed here do not represent statistical equilibrium conditions considered by Robe and Emanuel (1996), our results seem consistent with their equilibrium scaling.

\section{e. Cloud center of mass and cloud mass flux in all simulations}

Figure 11 shows evolutions of the total condensate center of mass (section 3b in Grabowski et al. 2006) and the upward cloud mass flux at the condensate center of 

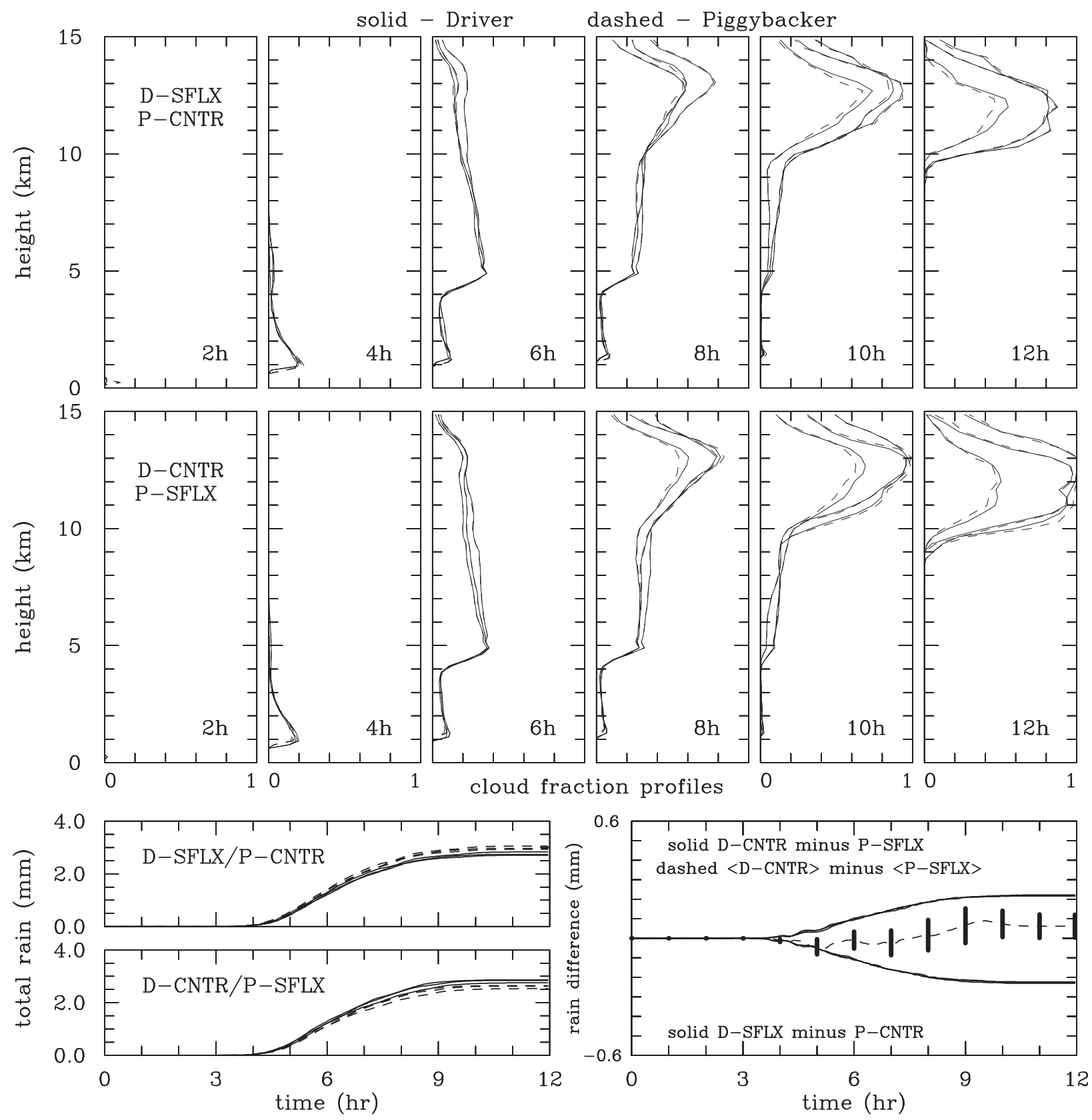

FIG. 7. As in Fig. 2, but for the CNTR-SFLX mini-ensemble.

mass height in drivers of all simulations discussed here and in PRI and POL from GM16. The mass flux is defined as $1 / N \Sigma \alpha \rho w$, where summation is over all points $N$ at a given level, $\rho$ is the air density, $w$ is the local updraft speed, $\alpha=1$ if $w>0$, and the total condensate (sum of cloud and precipitation mixing ratios) is nonzero and $\alpha=0$ otherwise. The data come from the 6-min archive with values for each hour averaged among all ensemble drivers at a given hour and including two neighboring time levels (i.e., $6 \mathrm{~min}$ prior to and after the full hour).
The symbols are spread around a given hour so they do not overlay each other. The vertical lines show twice the standard deviation among all data points included in the averaging. In retrospect, it would probably help if the updraft mass flux is saved in a similar manner as the surface precipitation (i.e., averaged over every model time step and saved twice more frequently). This is because the differences are arguably not statistically significant except of a few data points. As the figure shows, the center of mass gradually rises as the simulation 

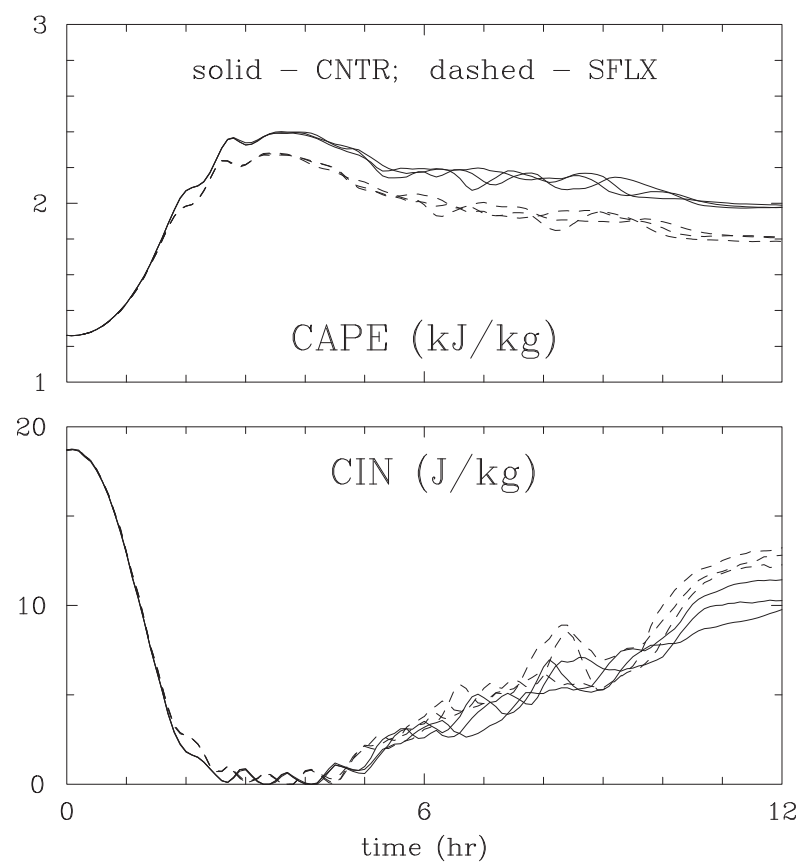

FIG. 8. As in Fig. 4, but for the CNTR-SFLX mini-ensemble.

progresses. Prior to hour 6, the height is similar in all simulations. After hour 6, the spread increases, although it is difficult to separate microphysical effects (i.e., POL vs PRI) from those of meteorological factors considered in SNDG, RHUM, SFLX, and FORC simulations. All simulations converge in the final hour. The evolution of the upward cloud mass flux at the center of mass is similar for all simulations, with the only possibly statistically significant difference being the mass flux at hour 6 of the FORC simulation.

\section{GATE observations}

Among the simulations discussed above, perhaps the impact of the additional forcing that the large-scale ascent provides is the most striking. In particular, as suggested by the CAPE and CIN evolutions, atmospheric stability is practically the same regardless of the presence or absence of the additional large-scale ascent, but surface rain accumulation is significantly modified. If there are changes in aerosols that accompany the additional ascent, the increased precipitation could be erroneously attributed to aerosols. One may then ask whether the lack of connection between the state of the atmosphere (e.g., CAPE) and the mean precipitation is also true for the natural fields of deep convective clouds. To explore that issue we use observations collected during Phase III of GATE of 1974 in the tropical eastern Atlantic. These data (Sui and Yanai 1986 and references therein) have been used in cloud-resolving model simulations discussed in Grabowski et al. $(1996,1998)$. The 7-day period selected for the simulations feature distinct convection periods associated with changing large-scale meteorology. In particular, the period featured the nonsquall cluster on 2 September, the squall line on 4 September, and unorganized convection on 7 September. As shown in Fig. 1 of Grabowski et al. (1998), the large-scale forcing during deep convection events was large, down to $-20 \mathrm{~K} \mathrm{day}^{-1}$ for the temperature and up to $5 \mathrm{~g} \mathrm{~kg}^{-1} \mathrm{day}^{-1}$ for the water vapor (i.e., almost an order of magnitude larger than what is considered in the FORC simulations). The nonsquall cluster was associated with large forcing and weak large-scale shear, and a squall line developed in the strongly sheared environment associated with an easterly wave moving into the tropical eastern Atlantic from the African continent.

Figure 12 shows data from the $3^{\circ}$ by $3^{\circ}$ inner GATE hexagon array and used in simulations described by Grabowski et al. (1998). The bottom panel shows the estimate of the 6-h surface rain accumulation. The periods with large precipitation correspond to the nonsquall clusters on 2 September and the squall line on 4 September. The second panel from the bottom shows evolution of the diagnosed large-scale ascent over the inner GATE hexagon, with vertical velocities up to several centimeters per second for periods of significant surface precipitation. The third panel from the bottom shows evolution of CAPE [CAPE is also shown in Fig. 18 of Grabowski et al. (1998); the pattern is the same but the values are lower here because the analysis used here applies the initial parcel temperature and moisture averaged over the 500-m-deep layer near the surface rather than just the surface values in Grabowski et al.]. The three lower panels show the well-known fact that CAPE is a poor predictor of convection on time scales longer than several hours. In fact, CAPE is the lowest for periods with large surface precipitation, arguably because of the impact on downdrafts and precipitation on the lower-tropospheric temperature and humidity. The top two panels of Fig. 12 show evolutions of the temperature at 5 and $10 \mathrm{~km}$. The temperature at $5 \mathrm{~km}$ varies little over the 7-day period. This is in agreement with the fact that the temperature in the tropics varies little because of the action of gravity waves that in the convecting atmosphere efficiently homogenize horizontal temperature gradients. This idea is behind the weak temperature gradient approximation (e.g., Sobel et al. 2001), as already mentioned in the introduction. The temperature at $10 \mathrm{~km}$ varies more significantly. However, the variations are dominated by the diurnal cycle, with larger variations corresponding to larger surface precipitation and arguably larger upper-tropospheric anvils that interact with solar and Earth's thermal radiation. 

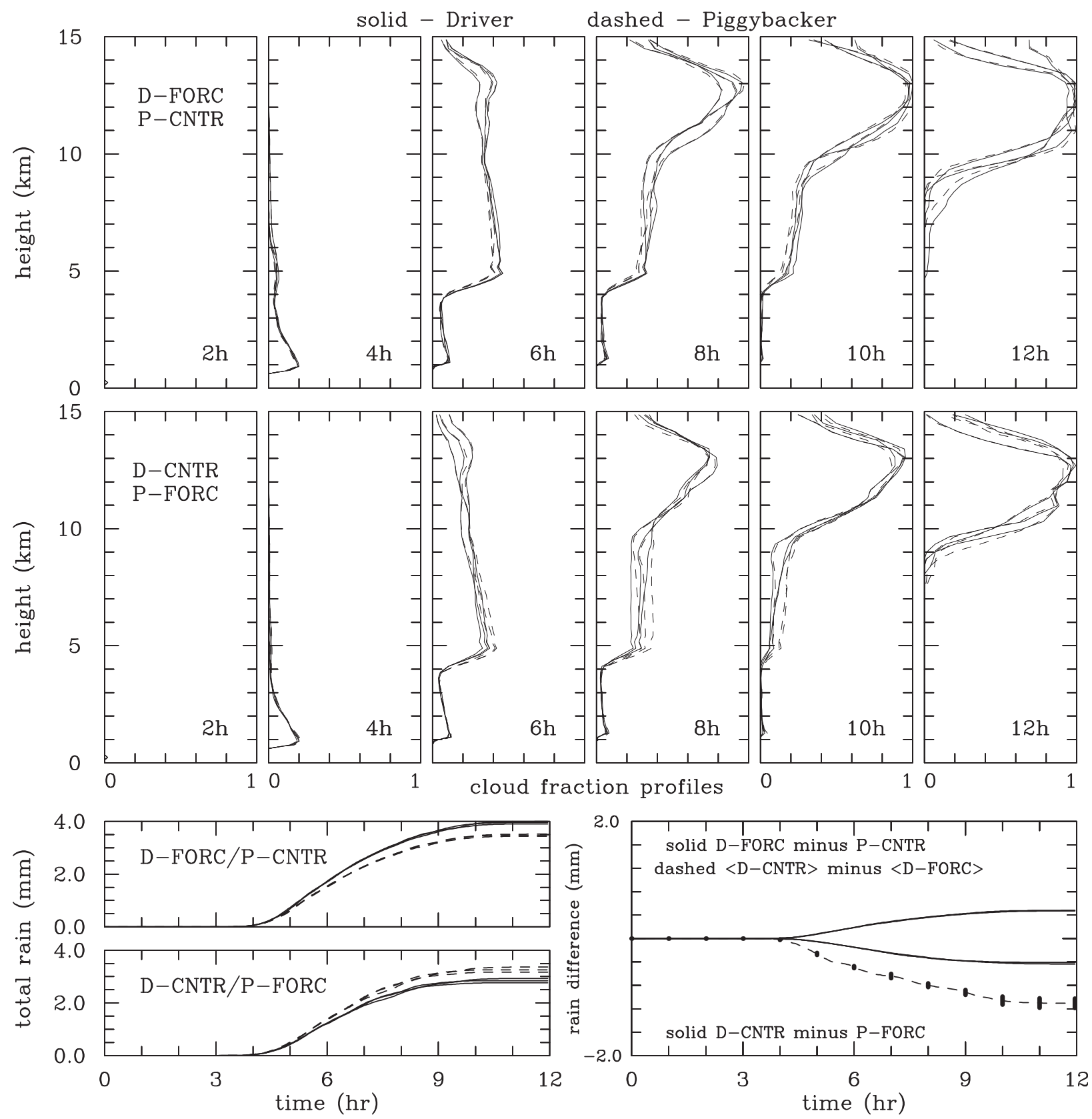

FIG. 9. As in Fig. 2, but for the CNTR-FORC mini-ensemble.

In summary, the GATE data show that precipitation from deep convection, at least in the tropics, is notoriously difficult to constrain using available observations. The estimate of the surface precipitation shown in Fig. 12 comes from the radar data that have a significant margin of error. For instance, evolution of the surface precipitation based on the moisture budget for the GATE inner array is significantly different from the radar estimate (see Fig. 8 in Grabowski et al. 1998) although the 7 -day mean is relatively close $\left(0.57\right.$ vs $\left.0.49 \mathrm{~mm} \mathrm{~h}^{-1}\right)$.
It follows that any attempt to separate aerosol impact from effects of meteorological conditions for tropical convection would be very difficult, if not impossible. This is in stark contrast to claims in observational studies mentioned in the introduction.

\section{Conclusions}

To answer the question posed in the title, a piggybacking methodology used to study effects of microphysical 

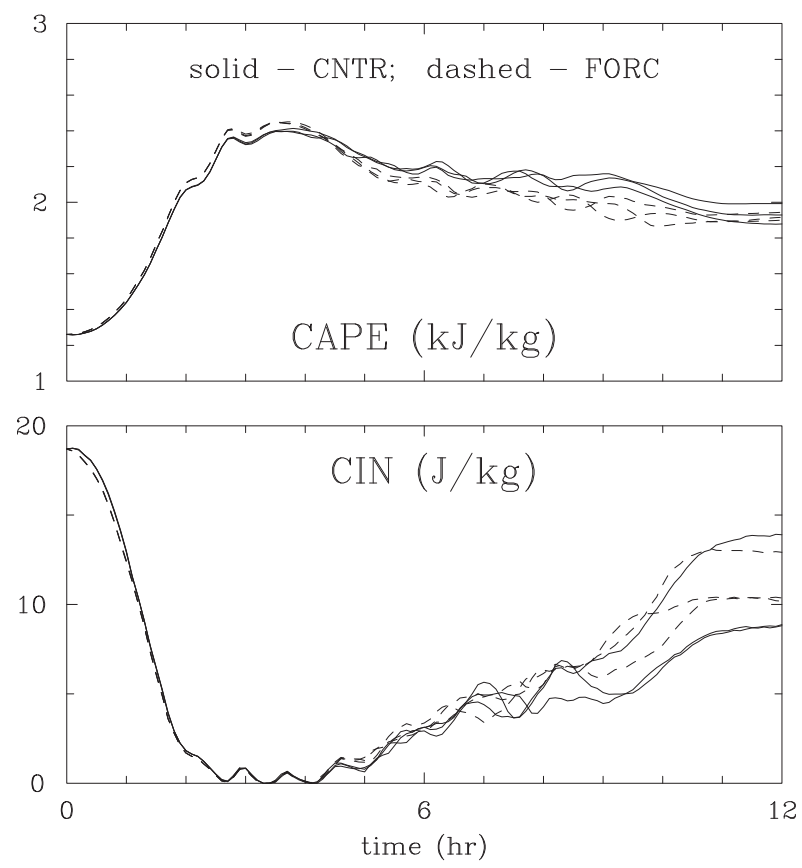

FIG. 10. As in Fig. 4, but for the CNTR-FORC mini-ensemble.

parameterizations and aerosols in shallow and deep convection simulations is extended to study other factors affecting the dynamics of moist convection, such as the initial sounding, surface heat fluxes, and additional forcing through the large-scale ascent. All these factors have a significant impact on the development and intensity of convection as documented in numerous publications describing observations and simulations of moist convection (e.g., Emanuel 1994; Cotton et al. 2010). However, the key idea explored in this paper is to introduce small changes to these environmental factors (i.e., to the meteorology) and extract the specific impacts on clouds and precipitation. Amplitudes of the changes, although arbitrary, are argued to be representative of the accuracy of atmospheric measurements, say, several tenths of $1 \mathrm{~K}$ for the temperature and several percent for the relative humidity (e.g., Nash 2015), $10 \%-20 \%$ of the surface heat fluxes, and $1 \mathrm{~cm} \mathrm{~s}^{-1}$ (or maybe even larger) for the large-scale vertical velocity. As in GM16, we focus on the impacts on the uppertropospheric clouds and on the surface precipitation as these are used (or can be used) as observable parameters describing macroscopic properties of deep convection. The same modeling setup mimicking daytime convective development over land and featuring unorganized deep convection is used, following Grabowski et al. (2006) and GM16. The key conclusion is that the impact of the perturbations considered here is comparable to the aerosol effects discussed in GM16.

How then can one separate the effects of aerosols from the impact of meteorological conditions? The

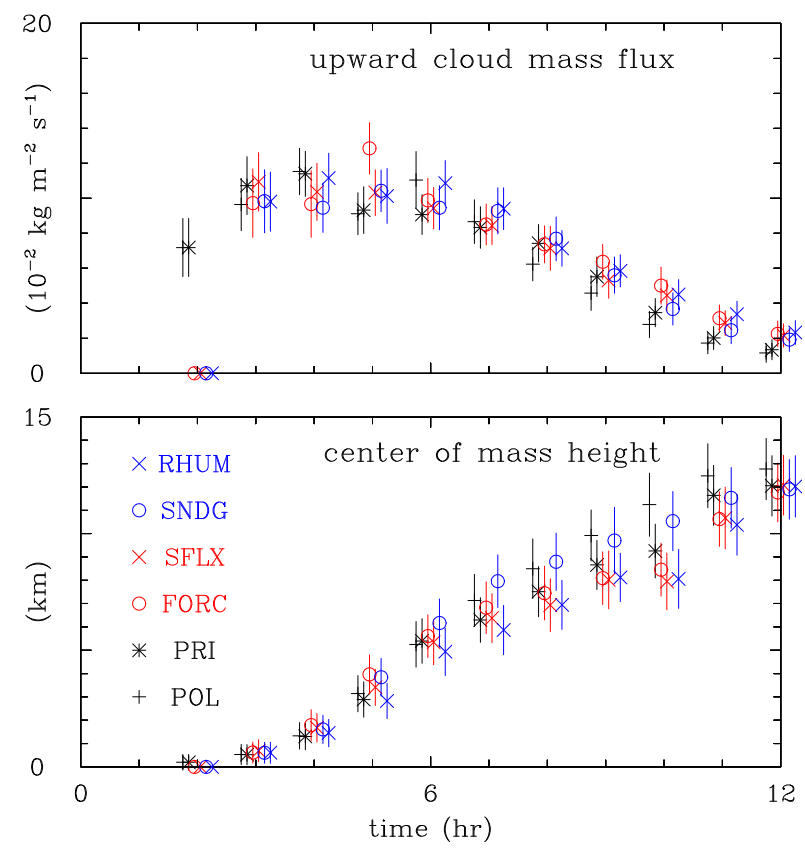

FIG. 11. (bottom) The height of the center of mass and (top) upward cloud mass flux at the center of mass for PRI and POL simulations from GM16 (black) and for FORC and SFL (red) and SNDG and RHUM (blue) drivers. Data are averaged among ensemble members and in time, as explained in text, and are shown every hour, with data points shifted in the horizontal around the hour for a better display. The thin vertical lines represent twice the standard deviation of the ensemble spread. The key in the bottom panel shows symbols and colors used in both panels.

results suggest that this is simply not possible. Taking the simulations with additional forcing as the key example, and keeping GATE observations in mind, there is very little that distinguishes observable convective parameters (e.g., CAPE) with and without the additional forcing. Yet, there are significant differences in the surface precipitation and upper-tropospheric cloudiness that could be incorrectly attributed to aerosols. This is because of the fundamental way deep convection operates, at least in the tropics, in essence maintaining similar thermodynamic states and drastically different cloudiness and precipitation (e.g., Robe and Emanuel 1996). The simulations presented here suggest that the quasiequilibrium arguments can be extended to the diurnal convective development as well, arguably because the gravity wave adjustment is much faster than environmental changes resulting from diurnal surface forcing over summertime continents.

Piggybacking reduces the impact of different realizations of the convective cloud field as discussed in Grabowski (2014, 2015). For short simulations (e.g., a day or two as in Gayatri et al. 2017), the impact of different realizations needs to be carefully separated from 


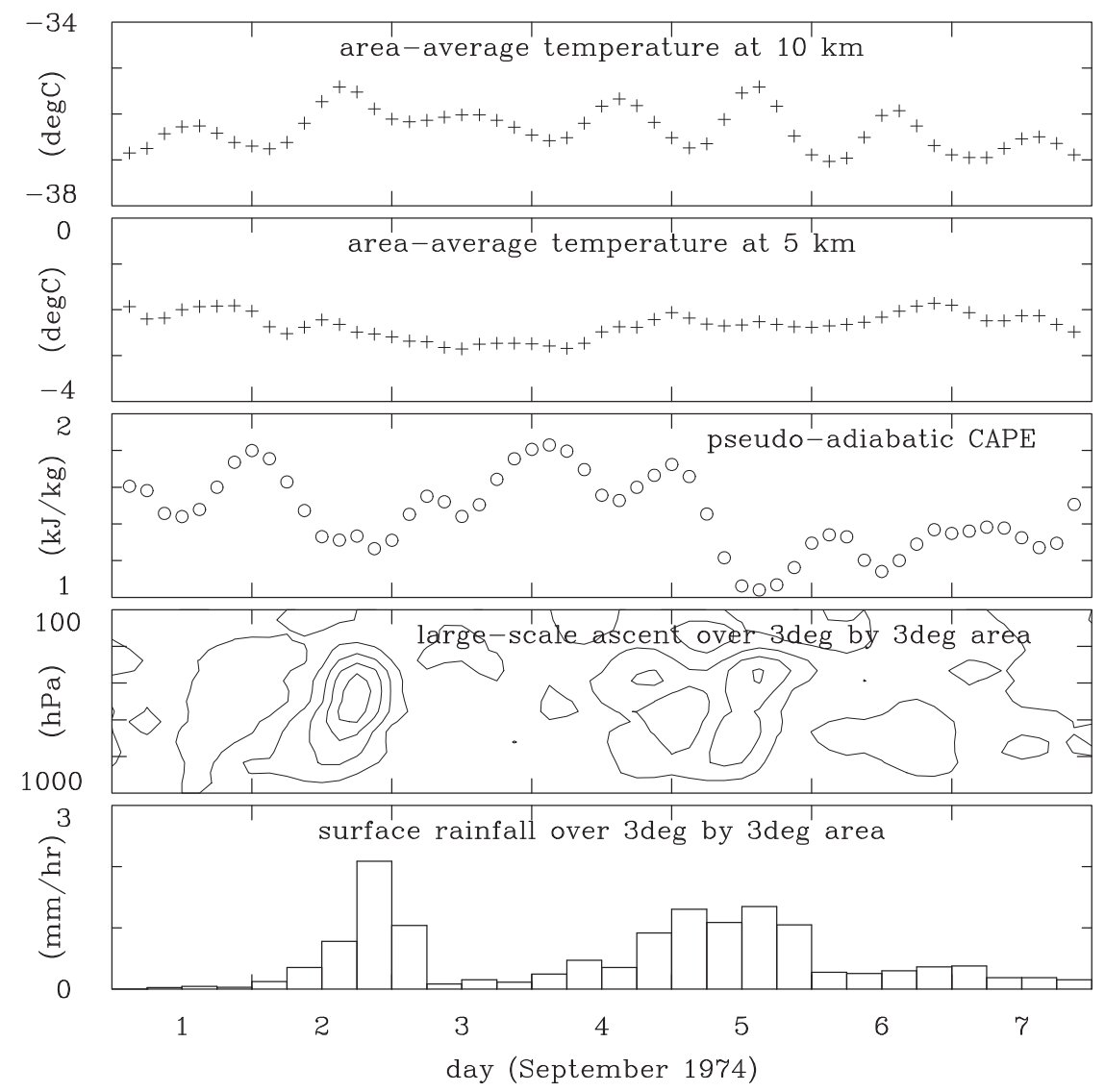

FIG. 12. Data for 7-day period from the GATE Phase III observations. (top two rows) Evolutions of the air temperature at 10- and 5-km altitudes, respectively. (third row) Evolution of CAPE calculated from the sounding data. (fourth row) Time-height contour plot of the large-scale ascent averaged over the $3^{\circ}$ by $3^{\circ}$ inner GATE sounding array (contour interval is $1 \mathrm{~cm} \mathrm{~s}^{-1}$ ). (bottom row) The estimate of the surface precipitation.

aerosol effects. This is illustrated in Fig. 8c in Gayatri et al. (2017) that compares surface rain accumulations over the entire computational domain and over a small subdomain approximately covering the region with available observations. The accumulations over the entire domain increase a mere few percent when $\mathrm{CCN}$ is increased from 100 to $3000 \mathrm{~cm}^{-3}$. However, the accumulation over the observational domain increases much stronger (and, coincidentally one may argue, with increasing CCN) simply because different convective systems develop over the subdomain (cf. Fig. 7 therein). Applying the piggybacking technique to simulations as in Gayatri et al. (2017) would allow accurate estimation of aerosol effects over a subdomain as well. Work is in progress to incorporate the piggybacking technique into the NCAR's Weather Research and Forecasting (WRF) Model used in the Gayatri et al. (2017) study.

Finally, the novel use of the piggybacking methodology presented here paves the way to other applications of this technique in the future. For instance, there is a growing consensus that the warming climate leads to the increase of climate extremes, for instance, extreme surface rainfall (e.g., Westra et al. 2014; Ban et al. 2015). Piggybacking can help untangle dynamical and thermodynamical impacts on deep convection, that is, differentiate effects resulting from modified cloud dynamics (e.g., stronger updrafts) and effects tied to the increased capability of warmer air to hold more water vapor, similarly to the clear separation of dynamical and microphysical impacts that piggybacking allows in GM16. We hope to report on such studies in the future.

Acknowledgments. This work was partially supported by the U.S. DOE ASR Grant DE-SC0016476. Assistance from Bob Dattore from NCAR's CISL Data Support Section in converting the old GATE dataset into a format readable on contemporary computers is greatly appreciated. Comments on the early version of this manuscript by Hugh Morrison, Andreas Prein, and Adam Varble are acknowledged. The National Center 
for Atmospheric Research is sponsored by the National Science Foundation.

\section{REFERENCES}

Andreae, M. O., D. Rosenfeld, P. Artaxo, A. A. Costa, G. P. Frank, K. M. Longo, and M. A. F. Silva-Dias, 2004: Smoking rain clouds over the Amazon. Science, 303, 1337-1342, https://doi.org/ 10.1126/science.1092779.

Ban, N., J. Schmidli, and C. Schär, 2015: Heavy precipitation in a changing climate: Does short-term summer precipitation increase faster? Geophys. Res. Lett., 42, 1165-1172, https://doi.org/ 10.1002/2014GL062588.

Bretherton, C. S., and P. K. Smolarkiewicz, 1989: Gravity waves, compensating subsidence and detrainment around cumulus clouds. J. Atmos. Sci., 46, 740-759, https://doi.org/10.1175/ 1520-0469(1989)046<0740:GWCSAD > 2.0.CO;2.

Cotton, W. R., G. H. Bryan, and S. C. van den Heever, 2010: Storm and Cloud Dynamics. 2nd ed. Academic Press, 820 pp.

Derbyshire, S. H., I. Beau, P. Bechtold, J.-Y. Grandpeix, J.-M. Piriou, J.-L. Redelsperger, and P. M. M. Soares, 2004: Sensitivity of moist convection to environmental humidity. Quart. J. Roy. Meteor. Soc., 130, 3055-3079, https://doi.org/10.1256/ qj. 03.130 .

Emanuel, K. A., 1994: Atmospheric Convection. Oxford University Press, $580 \mathrm{pp}$

Fan, J., L. R. Leung, D. Rosenfeld, Q. Chen, Z. Li, J. Zhang, and H. Yan, 2013: Microphysical effects determine macrophysical response for aerosol impacts on deep convective clouds. Proc. Natl. Acad. Sci. USA, 110, E4581-E4590, https://doi.org/ 10.1073/pnas.1316830110.

—-, Y. Wang, D. Rosenfeld, and X. Liu, 2016: Review of aerosol-cloud interactions: Mechanisms, significance, and challenges. J. Atmos. Sci., 73, 4221-4252, https://doi.org/ 10.1175/JAS-D-16-0037.1.

Gayatri, K., S. Patade, and T. V. Prabha, 2017: Aerosol-cloud interaction in deep convective clouds over the Indian Peninsula using spectral (bin) microphysics. J. Atmos. Sci., 74, 31453166, https://doi.org/10.1175/JAS-D-17-0034.1.

Grabowski, W. W., 2014: Extracting microphysical impacts in large-eddy simulations of shallow convection. J. Atmos. Sci., 71, 4493-4499, https://doi.org/10.1175/JAS-D-14-0231.1.

2015: Untangling microphysical impacts on deep convection applying a novel modeling methodology. J. Atmos. Sci., 72, 2446-2464, https://doi.org/10.1175/JAS-D-14-0307.1.

—, and D. Jarecka, 2015: Modeling condensation in shallow nonprecipitating convection. J. Atmos. Sci., 72, 4661-4679, https://doi.org/10.1175/JAS-D-15-0091.1.

— , and H. Morrison, 2016: Untangling microphysical impacts on deep convection applying a novel modeling methodology. Part II: Double-moment microphysics. J. Atmos. Sci., 73, 3749-3770, https://doi.org/10.1175/JAS-D-15-0367.1.

_- and _- 2017: Modeling condensation in deep convection. J. Atmos. Sci., 74, 2247-2267, https://doi.org/10.1175/ JAS-D-16-0255.1.

—, X. Wu, and M. W. Moncrieff, 1996: Cloud-resolving modeling of tropical cloud systems during Phase III of GATE. Part I: Two-dimensional experiments. J. Atmos. Sci., 53, 3684-3709, https://doi.org/10.1175/1520-0469(1996)053<3684: CRMOTC $>2.0 . \mathrm{CO} ; 2$.

,,,$- \longrightarrow$, and W. D. Hall, 1998: Cloud-resolving modeling of cloud systems during Phase III of GATE. Part II: Effects of resolution and the third spatial dimension. J. Atmos. Sci., 55, 3264-3282, https://doi.org/10.1175/1520-0469(1998)055<3264: CRMOCS $>2.0 . \mathrm{CO} ; 2$.

— , and Coauthors, 2006: Daytime convective development over land: A model intercomparison based on LBA observations. Quart. J. Roy. Meteor. Soc., 132, 317-344, https://doi.org/ 10.1256/qj.04.147.

Hansen, Z. R., and L. E. Back, 2015: Higher surface Bowen ratios ineffective at increasing updraft intensity. Geophys. Res. Lett., 42, 10 503-10 511, https://doi.org/10.1002/2015GL066878.

Khain, A., and A. Pokrovsky, 2004: Simulation of effects of atmospheric aerosols on deep turbulent convective clouds using a spectral microphysics mixed-phase cumulus cloud model. Part II: Sensitivity study. J. Atmos. Sci., 61, 2983-3001, https://doi.org/10.1175/JAS-3281.1.

- D. Rosenfeld, and A. Pokrovsky, 2005: Aerosol impact on the dynamics and microphysics of deep convective clouds. Quart. J. Roy. Meteor. Soc., 131, 2639-2663, https://doi.org/10.1256/ qj.04.62.

Koren, I., G. Feingold, and L. A. Remer, 2010: The invigoration of deep convective clouds over the Atlantic: Aerosol effect, meteorology or retrieval artifact? Atmos. Chem. Phys., 10, 8855-8872, https://doi.org/10.5194/acp-10-8855-2010.

Li, Z., F. Niu, J. Fan, Y. Liu, D. Rosenfeld, and Y. Ding, 2011: Long-term impacts of aerosols on the vertical development of clouds and precipitation. Nat. Geosci., 4, 888-894, https:// doi.org/10.1038/ngeo1313.

Morrison, H., and W. W. Grabowski, 2007: Comparison of bulk and bin warm-rain microphysics models using a kinematic framework. J. Atmos. Sci., 64, 2839-2861, https://doi.org/10.1175/ JAS3980.

_ and _ 2008a: Modeling supersaturation and subgrid-scale mixing with two-moment bulk warm microphysics. J. Atmos. Sci., 65, 792-812, https://doi.org/10.1175/2007JAS2374.1. , and - 2008b: A novel approach for representing ice microphysics in models: Description and tests using a kinematic framework. J. Atmos. Sci., 65, 1528-1548, https://doi.org/ 10.1175/2007JAS2491.1.

—_, and ——, 2011: Cloud-system resolving model simulations of aerosol indirect effects on tropical deep convection and its thermodynamic environment. Atmos. Chem. Phys., 11 10 503-10 523, https://doi.org/10.5194/acp-11-10503-2011.

Nash, J., 2015: Measurement of upper-air pressure, temperature and humidity. WMO Instruments and Observing Methods Rep. 121, 87 pp., http://library.wmo.int/pmb_ged/iom_121_ en.pdf.

Robe, F. R., and K. A. Emanuel, 1996: Moist convective scaling: Some inferences from three-dimensional cloud ensemble simulations. J. Atmos. Sci., 53, 3265-3275, https://doi.org/ 10.1175/1520-0469(1996)053<3265:MCSSIF>2.0.CO;2.

Rosenfeld, D., U. Lohmann, G. B. Raga, C. D. O'Dowd, M. Kulmala, S. Fuzzi, A. Reissell, and M. O. Andreae, 2008: Flood or drought: How do aerosols affect precipitation? Science, 321, 1309-1313, https://doi.org/10.1126/science.1160606.

Seifert, A., C. Köhler, and K. D. Beheng, 2012: Aerosol-cloud-precipitation effects over Germany as simulated by a convectivescale numerical weather prediction model. Atmos. Chem. Phys., 12, 709-725, https://doi.org/10.5194/acp-12-709-2012.

Slawinska, J., W. W. Grabowski, and H. Morrison, 2009: Impact of atmospheric aerosols on precipitation from deep organized convection: A prescribed-flow model study using doublemoment bulk microphysics. Quart. J. Roy. Meteor. Soc., 135 1906-1913, https://doi.org/10.1002/qj.450. 
Sobel, A. H., J. Nilsson, and L. M. Polvani, 2001: The weak temperature gradient approximation and balanced tropical moisture waves. J. Atmos. Sci., 58, 3650-3665, https://doi.org/ 10.1175/1520-0469(2001)058<3650:TWTGAA >2.0.CO;2.

Storer, R. L., S. C. van den Heever, and T. S. L'Ecuyer, 2014: Observations of aerosol-induced convective invigoration in the tropical east Atlantic. J. Geophys. Res. Atmos., 119, 3963 3975, https://doi.org/10.1002/2013JD020272.

Sui, C.-H., and M. Yanai, 1986: Cumulus ensemble effects on the large-scale vorticity and momentum fields of GATE. Part I: Observational evidence. J. Atmos. Sci., 43, 1618-1642, https:// doi.org/10.1175/1520-0469(1986)043<1618:CEEOTL>2.0.CO;2; Corrigendum, 46, 1630, https://doi.org/10.1175/1520-0469 (1989)046<1630:C >2.0.CO;2.

Szumowski, M. J., W. W. Grabowski, and H. T. Ochs III, 1998: Simple two-dimensional kinematic framework designed to test warm rain microphysical models. Atmos. Res., 45, 299326, https://doi.org/10.1016/S0169-8095(97)00082-3.

Takemi, T., O. Hirayama, and C. Liu, 2004: Factors responsible for the vertical development of tropical oceanic cumulus convection. Geophys. Res. Lett., 31, L11109, https://doi.org/ 10.1029/2004GL020225.

Tao, W.-K., X. Li, A. Khain, T. Matsui, S. Lang, and J. Simpson, 2007: Role of atmospheric aerosol concentration on deep convective precipitation: Cloud-resolving model simulations. J. Geophys. Res., 112, D24S18, https://doi.org/10.1029/2007JD008728.

J.-P. Chen, Z. Li, C. Wang, and C. Zhang, 2012: Impact of aerosols on convective clouds and precipitation. Rev. Geophys., 50, RG2001, https://doi.org/10.1029/2011RG000369.

Teller, A., and Z. Levin, 2006: The effects of aerosols on precipitation and dimensions of subtropical clouds: A sensitivity study using a numerical cloud model. Atmos. Chem. Phys., 6, 67-80, https://doi.org/10.5194/acp-6-67-2006.

Thomas, L., N. Malap, W. W. Grabowski, K. Dani, and T. V. Prabha, 2018: Convective environment in pre-monsoon and monsoon conditions over the Indian subcontinent: The impact of surface forcing. Atmos. Chem. Phys., 18, 7473-7488, https:// doi.org/10.5194/acp-18-7473-2018.

Varble, A., 2018: Erroneous attribution of deep convective invigoration to aerosol concentration. J. Atmos. Sci., 75, 13511368, https://doi.org/10.1175/JAS-D-17-0217.1.

Westra, S., and Coauthors, 2014: Future changes to the intensity and frequency of short-duration extreme rainfall. Rev. Geophys., 52, 522-555, https://doi.org/10.1002/2014RG000464.

Xu, K.-M., and D. A. Randall, 1996: Explicit simulation of cumulus ensembles with the GATE Phase III data: Comparison with observations. J. Atmos. Sci., 53, 3710-3736, https://doi.org/ 10.1175/1520-0469(1996)053<3710:ESOCEW>2.0.CO;2. 